\title{
Study on Risk Evaluation based on Occupational Exposure Evaluation and Carcinogenic Risk Simulation*
}

\author{
Qian Zhang ${ }^{1}$, Deyin Huang ${ }^{1}$, Mao Liu ${ }^{2}$ \\ ${ }^{1}$ Tianjin Bohai Chemical Industry Group Co., Tianjin 300051, China \\ Received 20 August 2014 \\ Accepted 27 October 2014
}

${ }^{2}$ Research Center of Urban Public Safety Nankai University, Tianjin 300071, China

\begin{abstract}
In order to provide the quantitative risk evaluation for 1,3-butadiene-expose, quantitative method using physiologically based pharmacokinetic model and dose-response model is applied to the carcinogenic risk evaluation for 1,3-butadiene-exposed workers. First, the internal dose of inhaled-1,3-butadiene in human beings is simulated by exposure related dose estimating model recommended by USEPA. Second, the internal dose is induced into calculating formula of carcinogenic risk. In order to determine the uncertainty of the cancer risk, Monte Carlo simulation is used to analyze the risk probability distribution. A large chemical enterprise in Tianjin is selected as the case study and carcinogenic risk evaluation for 1,3-butadiene-exposed workers is calculated. The results show that the cancer risk of 1,3-butadiene-exposed workers obviously exceeds $1 \times 10^{-4}$ the maximum acceptable risk level. It is necessary to take relevant measures to reduce risk.
\end{abstract}

Keywords: Risk evaluation, 1,3-Butadiene, Occupational exposure evaluation, Carcinogenic risk simulation.

\section{Introduction}

In recent years, as China's rapid industrial development, harmful factors of industrial production on human health increasingly have aroused widespread concern. As an important organic chemical material, 1,3-butadiene (BD) is widely used in synthetic rubber, synthetic resin, synthetic fibers, plasticizers and other petrochemicals and manufacturing industries. The international community is increasingly concerned about the carcinogenicity of 1,3 butadiene. Occupational epidemiology studies have shown that the carcinogenic risk of works suffering from 1,3-butadiene occupational exposure increased significantly. It is particularly important to assess the carcinogenic risk suffering from 1,3-butadiene occupational exposure.

In the normal production situation, most of the monitoring data of hazardous substances is below the occupational exposure limits, but some human definite carcinogen such as BD has carcinogenic effects on human even if in the condition of low concentration.
With development of the health risk assessment methods, the concept of the internal dose has been introduced into carcinogenic risk assessment. The internal dose is the exposure material quantity which remains in human body after absorption and transformation. More and more researchers apply physiologically based pharmacokinetic (PBPK) model into chemical dose - response evaluation studies ${ }^{[1]}$ and use internal dose instead of exposure dose in the risk assessment, which is considered more convincing and accurate $^{[2-3]}$.

The human internal dose of chemical substances calculated by PBPK model relates to several complicated metabolism differential equations. In order to solve the complex PBPK model calculations, researchers often use program methods, and the calculation program is generally written in ACSL ${ }^{[4-5]}$. Shi Jie et al. adopted the trichloroethylene PBPK model existing in Exposure Related Dose Estimating Model (ERDEM) to simulate human internal dose, which eliminated the need for complex programming. However, there is no research explaining how to self-build a PBPK model. This study

\footnotetext{
* This study was supported by Municipal Key Science and Technology Support Project of Tianjin (No. 13ZCZDSY02300).
} 
elaborates for this problem, and introduces the internal dose simulated by this method into the carcinogenic risk calculation.

The research content and method are shown in Fig. 1. Firstly, in ERDEM software, 1,3-butadiene internal dose is simulated by PBPK model which is built using metabolic parameters in the literature. Then, we substitute the internal dose in the multistage dose-response model to obtain the cancer risk. Finally, uncertainties in cancer risk assessment are analyzed by Monte Carlo simulation.

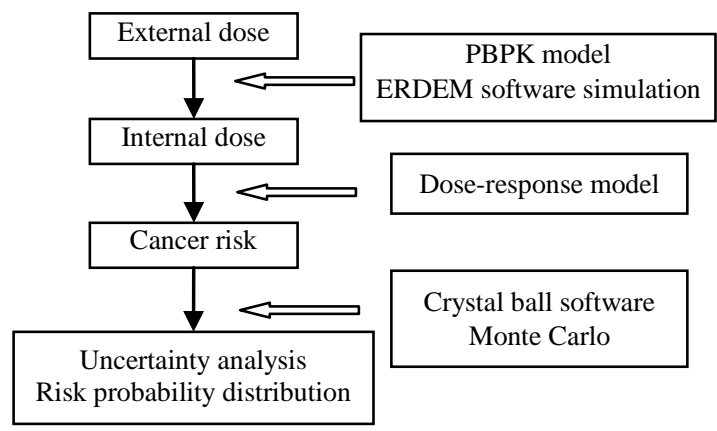

Figure 1. Research content and method

\section{Software Simulation of Dose Using ERDEM}

\section{Software Brief Introduction}

Exposure Related Dose Estimating Model (ERDEM) is a PBPK model simulation software in ACSL language and developed by EPA's National Exposure Research Laboratory. The metabolism of toxic substances in the body can be simulated by choosing compartments and entering metabolic and physiological parameters. The database includes data of epidemiological investigations and toxicology experiment, and also includes approved PBPK models of many toxicant and its metabolites. ERDEM provides the flexibility either to use existing models and to build new PBPK models to address specific science questions.

\section{Running Process}

Fig. 2 shows the running process which ERDEM builds PBPK model and simulates the internal dose. The running steps are as follows: (1)New modeling--Set the simulated chemical name and molecular weight in the appropriate interface. Fill in the name of model to be built, the exposing object to be studied, units and so on. (2) PBPK model organization and parameters setup--Select compartment and metabolic process, and input the organization parameters, metabolic rate, metabolic constants and so on. (3)Exposure parameters setup--Input exposure route, time, concentration, etc. (4) Output option setup--ERDEM can analyze chemical substances and their metabolites in different compartment, and give different output forms, such as concentration, AUC, volume, etc. So this step can set the output options to get the anticipant result forms. (5) Simulation running and result output--According to output options, ERDEM can give the internal dose quantity and curve over time.

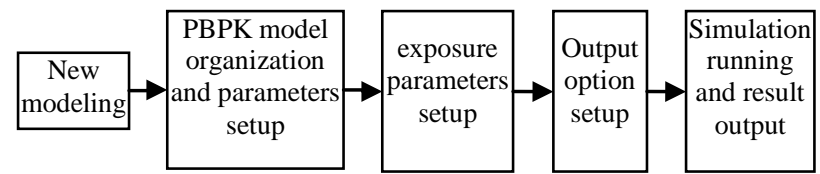

Figure 2. Running processes of ERDEM

\section{1,3-Butadiene PBPK Modeling}

The 1,3- butadiene exposure route considered in this paper is inhalation. When BD enters human body, it is metabolized to monoepoxide - - 1,2-epoxybutene, which will produce a variety of active metabolites. The metabolites can be conjugated with biological macromolecule, which results in changes of genetic material and inducing tumor ${ }^{[6-8]}$. The metabolic process of $\mathrm{BD}$ into 1,2- epoxybutene is the first step of the following metabolic process. According to related literature parameters ${ }^{[9]}$, this paper build 1,3-butadiene PBPK models of mouse and human, and compared with the experiment data.

Model includes six compartments, such as lung, blood, fat, liver, vessel-rich compartment and vessel-poor compartment. Metabolism to the monoepoxide is ascribed to the entire liver and is assumed to follow simple Michaelis-Menten kinetics. No further metabolism of epoxybutene is considered. S. Fustinoni et al. [10] pointed out when exposure concentration was low, the concentration of the $\mathrm{BD}$ which remained in human body after metabolism can be used as biomarker.

This paper use PBPK model to calculate BD blood concentration $\mathrm{d}$, which is regarded as the internal dose of internal dose-response relation $\mathrm{P}(\mathrm{d})$. Parameters and PBPK model are respectively shown as Table 1 and Fig. 3. 


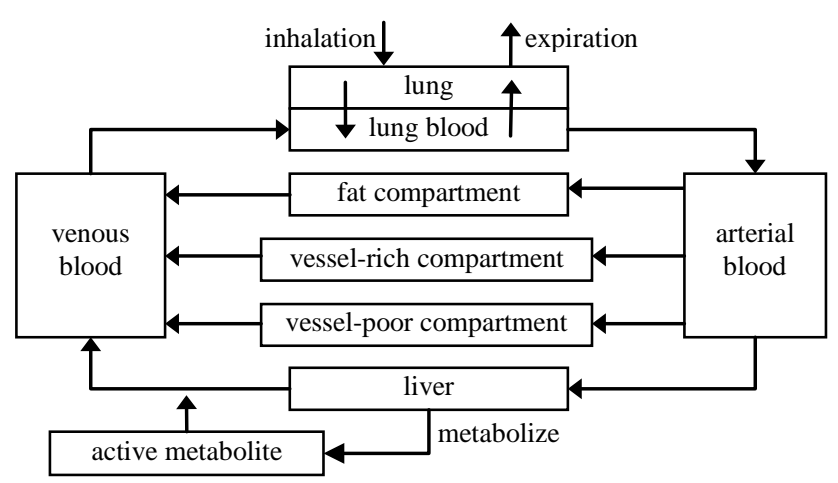

Figure 3. PBPK model by the respiratory metabolism after intake of BD

Table 1. 1,3-Butadine PBPK model parameters

\begin{tabular}{|c|c|c|c|c|c|}
\hline Parameters & mouse & human & Parameters & mouse & human \\
\hline $\begin{array}{l}\text { Physiological } \\
\text { parameters }\end{array}$ & & & $\begin{array}{l}\text { Volume } \\
\text { proportion }\end{array}$ & & \\
\hline Weight (kg) & 0.028 & 70 & Blood & 0.05 & 0.077 \\
\hline $\begin{array}{l}\text { Cardiac } \\
\text { output (L/h) }\end{array}$ & 1.044 & 660 & Fat & 0.04 & 0.144 \\
\hline $\begin{array}{l}\text { Alveolar } \\
\text { ventilation } \\
\text { (L/h) }\end{array}$ & 2.64 & 1,200 & Liver & 0.062 & 0.025 \\
\hline $\begin{array}{l}\text { Blood flow } \\
\text { proportion }\end{array}$ & & & $\begin{array}{l}\text { Vessel-rich } \\
\text { compartment }\end{array}$ & 0.05 & 0.037 \\
\hline Fat & 0.05 & 0.036 & $\begin{array}{l}\text { Vessel-poor } \\
\text { compartment }\end{array}$ & 0.78 & 0.547 \\
\hline Liver & 0.16 & 0.16 & $\begin{array}{l}\text { Partition } \\
\text { coefficients }\end{array}$ & & \\
\hline $\begin{array}{l}\text { Vessel-rich } \\
\text { compartment }\end{array}$ & 0.52 & 0.446 & Air & & .5 \\
\hline $\begin{array}{l}\text { Vessel-poor } \\
\text { compartment }\end{array}$ & 0.19 & 0.361 & Fat & & 8.2 \\
\hline $\begin{array}{l}\text { Metabolic } \\
\text { parameters }\end{array}$ & & & Liver & & 49 \\
\hline $\begin{array}{l}\text { Liver V } \\
\text { (nmol/h/mg) }\end{array}$ & 155.4 & 70.8 & $\begin{array}{l}\text { Vessel-rich } \\
\text { compartment }\end{array}$ & & 34 \\
\hline $\begin{array}{ll}\begin{array}{l}\text { Liver } \\
(\mathrm{mM})\end{array} & \mathrm{Km} \\
\end{array}$ & 0.002 & 0.00514 & $\begin{array}{l}\text { Vessel-poor } \\
\text { compartment }\end{array}$ & & 26 \\
\hline
\end{tabular}

IV. Verification of Simulation Results

In order to verify PBPK model simulation results, the mouse metabolic internal doses simulated by ERDEM software are compared with biological experimental data. Himmelstein et al. measured blood concentrations of 1,3-butadiene in mice exposed by nose-only inhalation to $62.5,625$, and $1,250 \mathrm{ppm}$ 1,3-butadiene for $6 \mathrm{~h}$. Steady-state blood concentrations of 1,3-butadiene were achieved by $2 \mathrm{~h}$.

BD internal dose accord with the experimental data as shown in the Fig.4, hence, PBPK model can predict and analyze the metabolism situation of BD in the body. However, there is no available 1,3-butadiene metabolic experimental data in human body, so human internal dose results are no further verified.

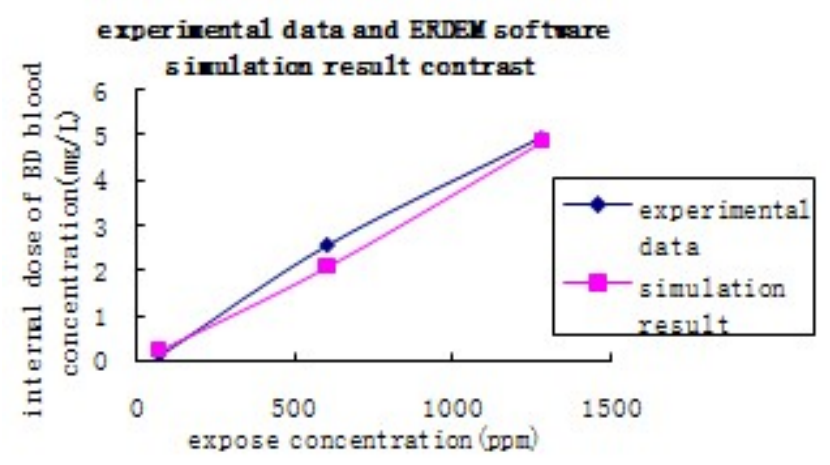

Figure 4. Experimental data and simulation results

\section{Carcinogenic Risk Calculation}

Dose response function of internal dose (d) to carcinogenic probability can be solved by several dose response model, such as probit model, logit model, weibull model, multi hit model, one hit, multistage model and so on, where multistage model is used most widely. USEPA indicate that multistage model should be recommended in the research of dose response relationship. According to the USEPA 1,3-butadiene risk assessment guideline ${ }^{[9]}$, this paper uses linear multistage model shown as follows:

$$
\mathrm{P}(\mathrm{d})=1-\exp \left[-\left(\mathrm{q}_{0}+1_{1} \mathrm{~d}^{1}+\mathrm{q}_{2} \mathrm{~d}^{2}+\ldots+\mathrm{q}_{\mathrm{k}} \mathrm{d}^{\mathrm{k}}\right)\right] \quad,
$$

parameter qi $\geqslant 0, \quad I=0,1, \cdots, k$.

In latest health assessment of 1,3 -butadiene ${ }^{[9]}$, Integrated Risk Information System (IRIS) point out that lots of epidemiological studies implicate BD is related to occupational contact crowd inducing Hodgkin's disease, leukemia, lymphosarcoma, lung cancer and so on. This paper attends to the calculation of occupational carcinogenic risk probability 1,3-butadiene. A 2-year chronic inhalation toxicity and carcinogenicity study on effects of 1,3-butadiene on B6C3F1 mice was conducted by National Toxicology Program (NTP). Based on tumor incidence of mouse and multistage model, carcinogenic 
probability function of 1,3-butadiene exposed workers is shown as follows:

$$
\mathrm{P}(\mathrm{d})=\frac{1-\exp \left[-281.44 \times \mathrm{d}^{2}-23.299 \times \mathrm{d}-0.5124\right]}{\mathrm{P}(0)_{\mathrm{A}}} \times \mathrm{P}(0)_{\mathrm{H}}
$$

where $P(d)$ represents the lifetime risk (probability) of cancer at internal dose d, P(0)A represents background risk value of animal cancer, which is 0.12 obtained from experimental result, $\mathrm{P}(0) \mathrm{H}=200 \times 10^{-6}$ represents background risk value of human cancer.

\section{Uncertainty Analysis}

In risk assessment, uncertainty which induces evaluation result cannot guarantee the reliability is always caused by randomicity of the objective world, our lack of knowledge and errors of evaluation method ${ }^{[12]}$.

Uncertainty of carcinogenic risk assessment in this paper is from the calculation of the internal dose and risk, which can be known from the research line. PBPK modeling in the calculation of the internal dose exists errors caused by animal experiment, and parameters also can cause uncertainties. Another uncertainty factor is interspecific differences and own errors of the dose response relationship in the process of carcinogenic risk calculation. These can affect the real risk reflection of calculation results in different degree, and induce uncertainties of the carcinogenic risk.

Monte Carlo Analysis (MCA) is one of the commonly used uncertainty analysis methods ${ }^{[13]}$, and applies probability method to analyze the uncertainty and risk assessment characterization. Monte Carlo simulation of cancer risk in this paper is operated by Crystal Ball, which analyzes the uncertainty from risk probability distribution.

\section{Case Study}

This method of carcinogenic risk assessment for 1,3-butadiene is applied into a large chemical enterprise in Tianjin. The concentration monitoring method of hazardous material in the air of workplaces complies with solvent desorption gas chromatography in determining 1,3-butadiene regulated in "Determination of alkenes in the air of workplace” (GBZ/T160.39-2007). Method of air sample collection complies with "Specifications of air sampling for hazardous substances monitoring in the workplace” (GBZ159-2004). Field monitoring is made on 1,3-budatiene concentration in the air of workplaces, and 112 samples are collected in three consecutive days. According to the measured data of BD, internal dose of 1,3-butadiene exposed workers are simulated by ERDEM software. BD blood concentration after in vivo metabolism is obtained by setting continuous exposure for 8 hours, and substituted in (2) of dose response relationship to get 1,3-butadiene carcinogenic risk value.

Table 2 shows the mathematical statistics results of BD actual measured concentration and the simulatioin results of internal dose and carcinogenic risk. Finally, the uncertainty of carcinogenic risk is analyzed by Monte Carlo simulation. Fig. 5 and 6 respectively show the risk probability distribution and probability distribution obtained by Crystal ball software. The results show that the cancer risk of workers in this enterprise is $6.52 \times 10^{-4} \sim 1.24 \times 10^{-3}$, and the average value is $7.20 \times 10^{-4}$. Generally, the risk level of $1 \times 10^{-4}$ is used as maximum acceptable risk $^{[14]}$. The risk values are all above $1 \times 10^{-4}$ according to the simulation results by Crystal ball, as shown in the Table 2.

Table 2. Actual monitoring concentration, internal dose by simulation and cancer risk

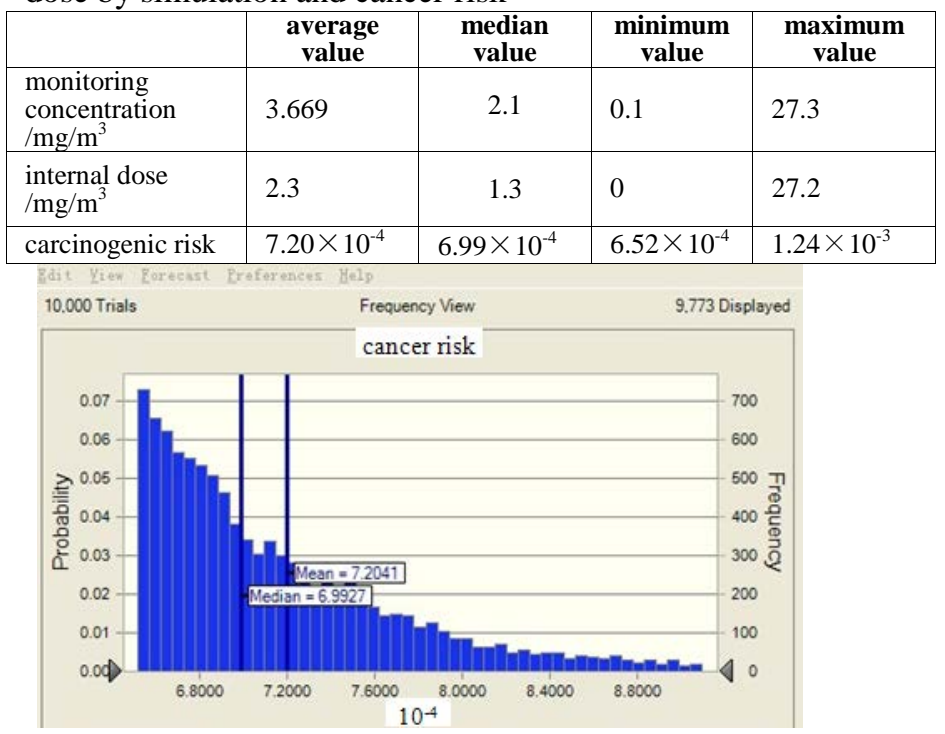

Figure 5. Probability distribution of 1,3-butadiene cancer risk 


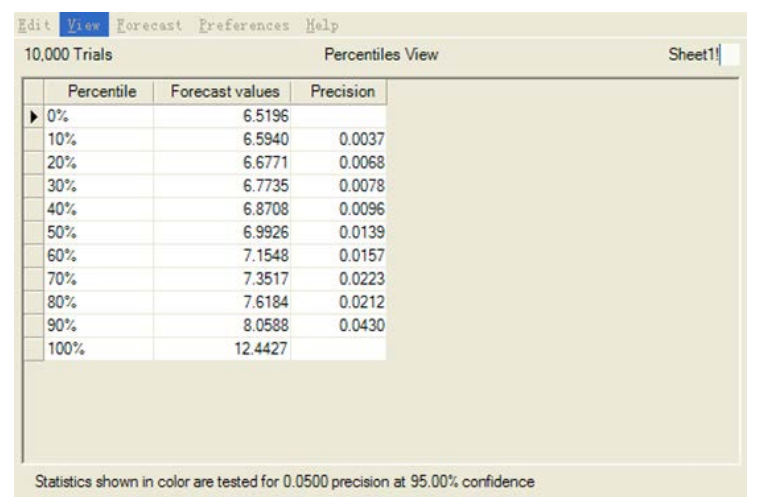

Figure 6. Percentile distribution of cancer risk

\section{Discussion and Conclusion}

1)To provide the theoretical basis of quantitative research for occupational health risk in China, carcinogenic risk for 1,3-butadiene-exposed workers is evaluated by physiologically based pharmacokinetic (PBPK) model and multistage dose-response relationship. Firstly, internal dose of 1,3-butadiene is analyzed by ERDEM which is a PBPK model simulation software recommended by USEPA. Then, carcinogenic risk is calculated by substituting internal dose into the function of carcinogenic risk. Finally, risk probability distribution is simulated by Monte Carlo method to analyze the uncertainty.

2) This research method of carcinogenic risk evaluation for 1,3-butadiene-exposed workers is applied in the case of a chemical enterprise in Tianjin. The result shows that occupational carcinogenic risk for BD exposed is higher than acceptable risk level of chemical enterprise, and it should adopt corresponding measures to reduce risk.

3) Although uncertainty is analyzed, PBPK model, parameters and experimental research related in dose-response relationship are cited from literature data which is mostly foreign. These cause variety of uncertainties, and in order to more conform to reality using localization data in the research is the main problems for further investigation.

\section{References}

[1] Krewski D, Withey J R, Ku Lung-fa, et al. Applications of physiologic pharmacokinetic modeling in carcinogenic risk
assessment[J]. Environmental Health Perspectives, 1994, Vol. 102(11): 37-50.

[2] LIU Shuyuan, WANG Hongqi.Health Risk Assessment of Organic Pollution in a Groundwater Source[J]. Environmental Science and Technology, 2014, Vol. 37(2): 174-177.

[3] ZHANG Qian, LIU Mao HUANG De-yin. Study on Carcin ogenic Risk Evaluation of Benzene-exposed Workers[J]. Ch ina Safety Science Journal, 2011, Vol. 21(5): 143-147.

[4] LU Ya-song, Raymond $\mathrm{S} \mathrm{H}$ Yang. Introduction to physiologically based pharmacokinetic model construction: an example of 1,1,1-trichloroethane[J]. Journal of Labour Medicine, 2006, Vol. 23(4): 330-338.

[5] SHI Jie. Analysis of acute health risk brought by accidental toxic gas leakage[D]. Tianjin: Nankai University , 2009.

[6] TAN Hong-shan, MIU Wen-bin, SUN Pin, et al. Updated research on 1,3-butadiene adducts. Occupational Health and Emergency Rescue, 2009, Vol. 27(6): 303 308.

[7] LIU Nan, CHENG Juan, LI Bin, et al. Research progress on 1,3-butadiene biomarkers. Foreign Medical Sciences(Section of Hygiene), 2007, Vol. 34(6): 352 357

[8] CHENG Xue-mei, JIAO Yan-ni, CHEN Jin-dong, et al. Stu dy on urine biomarkers in 1, 3-butadiene exposed workers [J]. Chinese Journal of Industrial Hygiene and Occupationa l Diseases, 2012, Vol. 30(9): 661-666.

[9] U.S. Environmental Protection Agency. Health Assessment of 1,3-Butadiene (EPA/600/P-98/001F). Washington, DC, 2002

[10] S. Fustinoni, L. Perbellini, L. Soleo, et al. Biological monitoring in occupational exposure to low levels of 1,3-butadiene. Toxicology Letters, Vol. 149(1-3):353-360.

[11] Matthew W. Himmelstein, Max J. Turner, Bahman Asgharian, et al.Comparison of blood concentrations of 1,3-butadiene and butadiene epoxides in mice and rats exposed to 1,3-butadiene by inhalation. Carcinogenesis, 1994, Vol. 15(8): 1479 1486

[12] WANG Li , HUANG De-yin, LIU Mao. Application of Monte-Carlo simulation method in cancer risk assessment $\mathrm{f}$ or benzene exposure [J]. Journal of Safety and Environment, 2011, Vol. 11(5): 231-235.

[13] Sassi G, Magnetti Vernai A, Ruggeri B. Quantitative estimation of uncertainty in human risk analysis[J]. Journal of Hazardous Materials, 2007, Vol. 145(1-2): 296-304.

[14] LI Yang, ZHOU Chang-yu, ZHANG Bo-jun. Study on acceptable level of risk in petrochemical industry[J]. Journal of Safety and Environment, 2007, Vol. 7(6): 116-119. 